\title{
O CEMESSC COMO GUARDIÃO DAS MEMÓRIAS DA EDUCAÇÃO DO SUL DE SANTA CATARINA
}

\author{
Marli de Oliveira Costa ${ }^{1}$ \\ Taise Machado Figueiredo²
}

\section{RESUMO}

O artigo busca apresentar o processo de implantação do Centro de Memória da Educação do Sul de Santa Catarina - CEMESSC, realizado pelo Grupo de Pesquisa História e Memória da Educação - GRUPEHME. Tem como objetivo compreender a importância do CEMESSC para a preservação e guarda da cultura material escolar das escolas estaduais mais antigas do Sul de Santa Catarina. A metodologia utilizada foi do tipo documental. Análise de relatórios e artigos sobre o CEMESSC, bem como alguns documentos que compõe o Centro. Além da investigação nesses documentos foi necessário revisitar uma vasta bibliografia que aborda os conceitos de cultura material escolar, principal referência nesse trabalho. O CEMESSC se apresenta como uma das formas de preservar, guardar e sociabilizar documentos iconográficos e textuais que contribuem para as pesquisas no campo da história da educação, possibilitando, por seu formato virtual a democratização a esses acervos.

Palavras-chave: Patrimônio Escolar. Cultura Material Escolar. Arquivos Escolares. Cultura do Descarte.

\section{EL CEMESSC COMO GUARDIÁN DE LAS MEMORIAS DE LA EDUCACIÓN DEL SUR DE SANTA CATARINA}

\section{RESUMEN}

El artículo búsqueda presentar el proceso de implantación del Centro de Memoria de la Educación del Sur de Santa Catarina - CEMESSC, realizado por el Grupo de Investigación Historia y Memoria de la Educación - GRUPEHME. Tiene como objetivo comprender la importancia del CEMESSC para la preservación y guardia de la cultura material escolar de las escuelas provinciales más antiguas del Sur de Santa Catarina. La metodología utilizada fue del tipo documental. Análisis de informes y artículos sobre el CEMESSC, así como algunos documentos que compone el Centro. Además de la investigación en esos documentos fue necesario revisitar una vasta bibliografía que aborda los conceptos de

\footnotetext{
${ }^{1}$ Possui graduação em Filosofia pela Universidade do Sul de Santa Catarina (1993), mestrado em História pela Universidade Federal de Santa Catarina (1999) e doutorado em educação pela Universidade Federal do Rio Grande do Sul (2009). E-mail: moc@unesc.net

2 Possui graduação em História pela Universidade do Extremo Sul Catarinense UNESC; Especialização em andamento em Educação, Diversidade e Proteção de redes sociais na UNESC. Email: taise.f88@gmail.com
}

Criar Educação, Criciúma, v. 7, no2, jul/dez 2018.-PPGE - UNESC 
cultura material escolar, principal referencia en ese trabajo. EI CEMESSC se presenta como una de las formas de preservar, guardar y sociabilizar documentos iconográficos y textuales que contribuyen para las investigaciones en el campo de la historia de la educación, posibilitando, por su formato virtual la democratización a esos acervos.

Palabras clave: Patrimonio Escolar. Cultura Material. Archivos Escolares. Cultura del Descarte.

\section{INTRODUÇÃO}

Este artigo busca apresentar a história da implantação do Centro de Memória da Educação do Sul de Santa Catarina - CEMESSC, em meio virtual. Para tanto problematiza, a partir da história da educação, a importância da preservação dos acervos escolares.

Meu interesse por essa temática deu-se porque participei como bolsista ${ }^{3}$ de Iniciação Científica na implantação desse Centro. O CEMESSC é um dos trabalhos de preservação dos acervos escolares desenvolvido pelo Grupo de Pesquisa, História e Memória da Educação- GRUPEHME. O projeto do Centro de memória da educação em meio virtual foi aprovado pelo Conselho Nacional de Desenvolvimento Científico e Tecnológico - CNPq em 2009, por meio do edital MCT/CNPq no 42/2007- Difusão e Popularização da C\&T.

O Projeto alcançou 27 escolas da rede pública estadual do sul de Santa Catarina. Ao fazer parte do grupo, tive a oportunidade de fazer visitas nas escolas selecionadas, podendo perceber a realidade dos arquivos das instituições, me deparando com uma triste realidade: a maioria das escolas não guardam adequadamente seus acervos.

Ao ter contado com os documentos, tive a oportunidade de conhecer ainda mais sobre a cultura material escolar. Estive presente em boa parte das escolas visitadas, onde auxiliei na escolha dos documentos e na coleta, também digitalizei os documentos encontrados, e participei na organização dos dados por meio de planilhas elaboradas pelas bibliotecárias ${ }^{4}$, para armazenar no site. Este trabalho está vinculado à Linha de Pesquisa da História da Educação, numa

\footnotetext{
${ }^{3} \mathrm{PIC}$ 170/CNPq/UNESC 2011 (PPGE/UNESC).

4 O CEMESSC recebeu auxílio técnico das bibliotecárias da Universidade. As planilhas de organização dos documentos para compor a página online, foram organizadas por elas, que ofereceram a orientação necessária para seu preenchimento.
}

Criar Educação, Criciúma, v. 7, no2, jul/nov 2018.- PPGE - UNESC 


\section{O CEMESSC E A CULTURA MATERIAL ESCOLAR: ENTRE A AMEÇA DO DESCARTE E OS DESAFIOS DA PRESERVAÇÃO}

O CEMESSC é um espaço de guarda e preservação da cultura material escolar do sul de Santa Catarina. A cultura material escolar encontra-se quase que diariamente ameaçada de descarte. Por isso, antes de discutir o processo de implantação desse Centro de Memória faz-se necessário revisitar o conceito e as discussões em torno da cultura material escolar e sua contribuição para a história da educação.

\section{QUE É CULTURA MATERIAL ESCOLAR}

O tema cultura material escolar está presente nas discussões de pesquisadores/as da história da educação. Esse conceito passa pelo conceito de Cultura.

Um conceito importante dentro das ciências humanas, que possui uma extensão de significados. Para simplificar, cultura abrange todas as realizações materiais e os aspectos espirituais praticados pelos humanos. Ou seja, tudo que a humanidade produz. Segundo José Luiz dos Santos (1996, p. 89), desde o século $\mathrm{XX}$ muitos estudos tem sido realizados com o intuito de hierarquizar todas as culturas humanas existentes ou extintas.

Margarida Louro Felgueiras (2010, p. 19) entende a importância da articulação dos estudos que envolvem a cultura com outras áreas do conhecimento, entre elas. A história:

A cultura como sistema de normas e valores e como conjunto de obrasprimas de uma época ou sociedade vai ocupar assim um lugar de destaque na narrativa, articulada com os processos sociais, econômicos e políticos, que a explicariam. Reconhece também a variedade das culturas e necessidades de as (re) conhecer, nas suas especificidades sóciohistóricas. 
Para Roger Chartier (2009, p. 34) podemos identificar a cultura com a própria história. Segundo o autor este termo - "cultura" - se encontra em duas procedências constituídas:

[...] a que designa as obras e os gestos que, em uma sociedade dada, se subtraem às urgências do cotidiano e se submetem a um juízo estético ou intelectual e a que aponta as práticas comuns por meio das quais uma sociedade ou um indivíduo vivem e refletem sobre sua relação com o mundo, com os outros ou com eles mesmos.

O autor evidencia que temos diversificadas formas e diferentes heranças e tradições, "[...] a história cultural privilegiou objetos, âmbitos e métodos diversos" (CHARTIER, 2009, p. 35).

Deste modo, entende-se que cultura vai além de conhecimentos, crenças, leis e costumes, ou seja, também é todo material ou objeto produzido pelos humanos, se solidificando em "Cultura Material".

A Cultura Material está diretamente ligada aos elementos produzidos pela sociedade, pois tudo que é considerado material é físico. É por meio de artefatos que podemos identificar como foi à cultura dos nossos antepassados. Os objetos enquanto artefatos:

[...] são fontes materiais aquelas por meio das quais os arqueólogos abordam as sociedades do passado, de maneira que, nas reconstituições que propõem, os aspectos materiais das civilizações prevalecem naturalmente. Todavia, deve-se recordar que, durante muito tempo, a arqueologia buscou essencialmente, nos vestígios concretos, as manifestações mentais sob todos os seus aspectos religiosos e artísticos. Portanto, a arqueologia não chegou de uma só vez à cultura material: foi-lhe necessário o exemplo da pré-história e o impacto da renovação das ciências humanas. (PESEZ, 2005, p. 240).

Assim, cultura material são coleções arqueológicas, acervos de museus, documentos, bibliografias, arquivos, fotografias, etc.. Segundo Jean-Marie Pesez (2005), a cultura material deve ser definida a partir de uma concepção de análise. A cultura material também alcança o âmbito escolar, contribuindo para a história da educação, ou seja, para a compreensão do universo dos educandários, bem como possibilita conhecer a sociedades e seus processo históricos.

[...] essas novas fontes que vêm sendo incorporadas pelas pesquisas mais recentes têm sido também transformadas no próprio objeto de pesquisa. $A$ imprensa pedagógica, o livro escolar, o caderno do aluno, o mobiliário, o uniforme, por exemplo, não servem apenas para nos fazer aproximar de um 
aspecto da realidade que estamos investigando, mas eles próprios - suas condições de produção (e de circulação), seus usos, as transformações por que passam ao longo do tempo - passam a interessar, pois dizem também sobre um passado educacional. (LOPES, 2001, p. 82).

Os utensílios e objetos podem ser considerados importantes para cultura material escolar possibilitando a novas pesquisas, desta forma, esses objetos remetem ao tempo passado/presente, como Le Goff descreve:

A distinção entre o passado e presente é um elemento essencial da concepção do tempo. É, pois, uma operação fundamental da consciência e da ciência históricas. Como o presente não se pode limitar a um instante, a um ponto, a definição da estrutura do presente, seja ou não consciente, é um problema primordial da operação histórica. A definição do período contemporâneo nos programas escolares de história é um bom teste para esta definição do presente histórico. (LE GOFF, 2003, p. 207).

Lopes (2001) se refere aos objetos escolares como possibilidades de pesquisas nos estudos de História da Educação, assim, a autora cita alguns elementos que são encontradas em instituições escolares, como:

[...] Carteiras, utensílios diversos, cadernetas de professores, exercícios, provas, boletins escolares, livros de ocorrência, cadernos e trabalhos de alunos/as, uniformes, quadros-negros (ou de ardósia), bibliotecas escolares, livros dirigidos ao estudante ou ao professor muito podem dizer sobre métodos de ensino, disciplina, currículo, saberes escolares, formação de professores... (LOPES, 2001, p. 83).

Para a autora, no momento em que pesquisadores e pesquisadoras da educação entram em contato com esses objetos podem estabelecer a relações com o tema que buscam abordar.

As fotografias também são consideradas documentos históricos, sendo que correspondem a uma boa parte da cultura material escolar produzida nos educandários, essas iconografias tem suma importância de investigação neste campo.

[...] Fotografias, gravuras e desenhos (inclusive infantis) podem trazer elementos para o entendimento dos modos como os artefatos foram sendo introduzidos nas escolas e indiciar as formas de sua apropriação pelos sujeitos em situações escolares. É preciso reconhecer que a instituição escolar tem sido profícua em produzir representações oficiais de seus sujeitos, dos espaços e, mesmo, das práticas escolares. (VIDAL e SILVA, 2011, p. 33). 


\section{Segundo Bóris Kossoy (1989), é importante estudar as fotografias na} medida em que os conteúdos das imagens podem trazer informações que auxiliam no conhecimento dos processos de construção de uma determinada sociedade.

[...] A fotografia, uma das invenções que ocorre naquele contexto, teria papel fundamental enquanto possibilidade inovadora de informação e conhecimento, instrumento de apoio á pesquisa nos diferentes campos da ciência e também como forma de expressão artística. (KOSSOY, 1989, p. 14).

Kossoy (1989, p. 16) afirma que "[...] é a fotografia um intrigante documento visual cujo conteúdo é a um só tempo revelador de informações e denotador de emoções".

Percebe-se em muitas fotografias encontradas nos educandários, imagens que mostram um período ocorrido no passado, recheado de informações e sentimentos de tal época, por exemplo: álbuns de fotografias de formandos dos cursos regionais e dos grupos escolares, eventos escolares, eventos culturais, desfiles cívicos, apresentações, viagens, fotos de professores, dos alunos/as e diretores, comemorações, etc..

\footnotetext{
Ver fotografias escolares como analisadores e, assim, repletas de informações, significados e tensões culturais, requer também que reconheçamos a presença da ambigüidade. A ambigüidade intrínseca do status das imagens, tanto como substância material, contendo a informação, quanto como representação icônica, direciona nosso olhar para a relação parece-ser que todas as imagens incorporam. (FISCHMAN e CRUDER, 2003, p. 47)
}

Assim, ao analisar uma fotografia, percebe-se a importância da preservação desse documento e a sua contribuição para a história da educação, "muitos objetos, materiais e móveis que podem ser visualizados nas fotografias não compõem mais o acervo da escola" (ALCÂNTARA, 2011, p. 87).

Os processos de escolarização podem ser compreendidos por meio da cultura escolar. Esse entendimento nos remete a uma procura ainda mais minuciosa destes objetos como documentos, testemunhos do passado.

A cultura escolar referencia o modo de como as instituições agiam, trabalhavam e pensavam. Também nos faz ter conhecimento da sociedade em determinados períodos. De certa forma, podemos reconstruir a história. "(Re) construir a história de um grupo, de uma comunidade, de uma cidade junto aos Criar Educação, Criciúma, v. 7, n², jul/nov 2018.- PPGE - UNESC 
sujeitos que a viveram e construíram sonhos de futuro permite buscar um novo olhar sobre a história" (ARAUJO, 2009, p. 291).

O conceito de cultura escolar nos estudos da história da educação vem buscando compreender e explicar o universo escolar e os sujeitos que fizeram parte do seu cotidiano.

[...] Entendo o conceito de cultura escolar como possuidor de multiplicidade de interpretações capazes de apresentar fragmentos explicativos do universo escolar, aptos a contribuir para o estudo dos fragmentos explicativos do universo escolar, aptos a contribuir para o estudo dos fenômenos educacionais em seus mais variados aspectos históricos. (BENCOSTA, 2010, p. 42).

Portanto, compreende-se que cultura escolar é mais do que simples objetos antigos ou, como muitos se referem, objetos ou documentos "velhos", que não passam de uns amontoados de coisas sem utilidades. Pois, estes objetos trazem em si a concepção de cultura material escolar, e tem suma importância para a história da educação, possibilitando a muitos pesquisadores/as adentrar neste universo, "descobrindo" e "reconstruindo" a história a partir de sua investigação, perspectiva histórica, classificação, análise documental, interpretação e seus interesses entre outros, enquanto historiadores/as.

Marcus Levy Albino Bencosta (2010, p. 42) afirma que:

[...] Ademais, à medida que optamos por utilizar o conceito de cultura escolar enquanto expressão intrínseca dos fenômenos educacionais, nós não podemos perder de vista que ele ajuda a melhor trabalhar as fontes que tratam do universo escolar de nossas pesquisas, mas as fontes por si não são capazes de elaborar conceitos, cabendo ao pesquisador fazê-lo, fundamentado na construção e refinamento de suas análises interpretativas que ressignificam constantemente o passado.

Portanto, está diretamente ligada à produção do conhecimento voltandose para área da história da educação. Visto como cultura material escolar alcança documentos textuais, iconográficos e outros artefatos significativos para a história, desde uma simples carteira antiga, um sino que era utilizado para troca de horários, os mimeógrafos, projetores de slides, globos, mapas, troféus, medalhas, mobílias antigas entre outros.

\section{DOCUMENTOS ESCOLARES COMO LUGAR DE MEMÓRIAS PARA A HISTÓRIA DA EDUCAÇÃO}

Criar Educação, Criciúma, v. 7, no2, jul/nov 2018.- PPGE - UNESC 
Outro ponto a ser abordado diz respeito à importância da preservação dos documentos escolares como forma de ajudar na garantia de identidades que reportam ao patrimônio escolar.

Para análise acerca dos documentos, parte-se do princípio de que a história é fundamentada por meio de pesquisas documentais, desde os séculos $\mathrm{V} e$ IV a.C. essa prática já vinha sendo utilizada.

Além do conceito de documento é preciso revisitar os conceitos de acervo e arquivo.

Sobre os arquivos sabemos que:

Os arquivos como instituição, provavelmente, tiveram origem na antiga civilização grega. Nos séculos V e IV a.C. os atenienses guardavam seus documentos de valor no templo da mãe dos deuses, isto é, no Metroon, junto à corte de justiça na praça pública em Atenas. No templo conservavam-se os tratados, leis, minutas da assembléia popular e demais documentos oficiais [...] Esses documentos foram conservados e transmitidos desde os tempos primitivos, até talvez o século III da era cristã, na forma de rolos de papiro. (SCHELLENBERG, 2004, p. 25)

Compreende-se, desta forma, que os documentos fazem parte das representações da humanidade, servindo para pesquisas históricas por meio dos registros coletados das ações e desenvolvimento humano.

Jacques Le Goff (2003) referencia o documento como memória, ou seja, o autor remete a memória a dois tipos de materiais: os documentos e os monumentos. Assim, para Le Goff (2003) todo documento pode ser verdadeiro ou falso, dependendo das análises e pesquisas que serão produzidas por meio das escolhas e perspectivas históricas de cada pesquisador, desta forma o documento pode se tornar um monumento histórico como o autor se refere.

De fato, o que sobrevive não é o conjunto daquilo que existiu no passado, mas uma escolha efetuada quer pelas forças que operam no desenvolvimento temporal do mundo e da humanidade, quer pelos que dedicam à ciência do passado e do tempo que passa, os historiadores. (LE GOFF, 2003, p. 525)

Para Le Goff (2003) os monumentos são herança do passado, já os documentos são escolhas dos historiadores, que tem como objetivo o intuito de estudar e escrever sobre a história, narrando os fatos e acontecimentos mostrados pelos documentos, tendo como principal objetivo a utilização de provas verdadeiras. Criar Educação, Criciúma, v. 7, no2, jul/nov 2018.- PPGE - UNESC 
O termo latino documentum, derivado de decere, "ensinar", evoluiu para o significado de "prova" e é amplamente usado no vocabulário legislativo. É no século XVII que se difunde, na linguagem jurídica francesa, a expressão titres et documents, e o sentido moderno de testemunho histórico data apenas do início do século XIX. (LE GOFF, 2003, p. 525)

Assim, mesmo que seja considerada uma escolha, o documento tem posicionamento e fundamento ao evento histórico, apresentando-se como testemunha histórica ou, como Le Goff (2003, p.527) alega, "Além do mais, afirmase essencialmente como um testemunho escrito".

Compreendo de modo sucinto que documento é e pode ser usado nos estudos e pesquisas históricas, a fim de trazer informação de determinadas datas e épocas por meio das análises e registros. Por isso a grandeza da preservação dos documentos escolares, onde têm sido lócus neste campo do conhecimento.

Percebe-se a importância dos documentos, a partir de uma perspectiva histórica, sendo que vivemos em uma sociedade que tem como objetivos novos paradigmas, assim, perdendo os valores de seu tempo. A autora Myriam Santos (1993), em seu artigo "O Pesadelo da Amnésia Coletiva", nos remete a uma análise mais sociológica. Santos, em seu estudo, afirma que vivemos em uma sociedade vazia, ou, como a autora chama, de "amnésia coletiva".

Diversos sociólogos, ainda que partindo de análises bastante diferenciadas do que seja a sociedade contemporânea - capitalista, industrial burocrática, de consumo, pós-industrial, ou dos meios de comunicação de massa - definem homens e mulheres que vivem nessa sociedade como indivíduos vazios: de sentimentos, experiências de vida, laços pessoais e capacidade de julgamento. (SANTOS, 1993, p. 71).

Para um individuo a amnésia se dá pela ausência dos registros decorrido do passado. Santos (1993, p. 71) alega que "esses indivíduos não tem memória, pois as experiências de vida foram substituídas por informações, e as lembranças do passado constituem recuperação de dados".

Para Le Goff (2003, p. 421) a memória está além dos fenômenos biológicos, mas associada com a vida social.

[...] Os fenômenos da memória, tanto nos seus aspectos biológicos como nos psicológicos, mais não são do que os resultados de sistemas dinâmicos de organização e apenas existem "na medida em que a organização os mantém ou os reconstitui". 
Segundo o autor, a falta de memória está diretamente ligada com a ausência ou presença da escrita, ou seja, por meio das fontes produzidas pelos humanos que têm a função de guardar e conservar as ações produzidas pelas instituições, tendo em seu âmbito a organização da memória coletiva.

Pierre Nora (1993, p. 14) trata como "[...] A necessidade de memória é uma necessidade da história". Para o autor a memória enquanto história se dá por meio de algo concreto.

[...] Ela se apóia inteiramente sobre o que há de mais preciso no traço, mais material no vestígio, mais concreto no registro, mais visível na imagem. $\mathrm{O}$ movimento que começou com a escrita termina na alta fidelidade e na fita magnética. Menos a memória é vivida do interior, mais ela tem necessidade de suportes exteriores e de referências tangíveis de uma existência que só vive por meio delas. Daí a obsessão pelo arquivo que marca o contemporâneo e que afeta, ao mesmo tempo, a preservação integral de todo o presente e a preservação integral de todo o passado. O sentimento de um desaparecimento rápido e definitivo combina-se à preocupação com o exato significado do presente e com a incerteza do futuro para dar ao mais modesto dos vestígios. (NORA, 1993, p. 14).

Por isso a importância da preservação da memória por meio da salvaguarda da cultura material, pois vivemos em uma sociedade que tem como costume a obsessão por algo novo e consequentemente o descarte do antigo. Sobre essa prática Pierre Nora coloca que: "[...] Já não lamentamos o bastante em nossos predecessores a destruição ou o desaparecimento daquilo que nos permitiria saber, para não cair na mesma recriminação por parte de nossos sucessores?" (NORA, 1993, p. 14). Conforme Nora a lembrança dá-se inteiramente de um passado findo que tem como objetivo a sua reconstituição mais minuciosa. "[...] É uma memória registradora, que delega ao arquivo o cuidado de se lembrar por ela e desacelera os sinais onde ela se deposita" (NORA, 1993, p. 15).

Os estabelecimentos educacionais produzem grandes quantidades de documentos. Esses documentos trazem informações que ao longo dos anos vem sendo desenvolvidas pelas gestões dos educandários, bem como professores, alunos e pais envolvidos nas associações das escolas.

A escola é uma instituição, e como qualquer outra tem como organização de seu estabelecimento a produção de documentos, deste modo registrando as ações da vida escolar dos alunos/as, do corpo docente, direção e até da comunidade inserida em seu contexto, em escolas públicas e privadas. 

Memória Institucional (CEMI) do Instituto Superior de Educação do Rio de Janeiro (ISERJ) salienta a importância dos arquivos escolares, possibilitando pesquisas historiográficas sobre educação, para preservar os acervos existentes, transformando-os em cultura escolar.

Santos destaca em seu artigo "Centro De Memória Institucional: a cultura escolar nos arquivos" (2011), que os arquivos escolares ou os documentos produzidos nas escolas são de suma importância para a historiografia da educação.

$O$ documento como cultura material nos possibilita também estudar 0 processo de escolarização.

\begin{abstract}
Busca-se, com isso, interrogar os processos de constituição, no Brasil, de uma sociedade escolarizada, bem como os diversos fatores intervenientes, os limites e as possibilidades e, finalmente, os constrangimentos sociais, culturais políticos e econômicos postos em funcionamento, ou impostos, sobretudo aos grupos subalternos, pela generalização de uma cultura escolar, e, portanto, da escrita na sociedade brasileira. (FARIA; GOLÇALVES e VIDAL, 2004, p. 153).
\end{abstract}

Compreendendo a dimensão e o significado dos documentos para a história da educação, e por meio da preservação documental que podemos adentrar em um universo de conhecimentos, que nos possibilita conhecer a vida social passada e presente, política e pedagógica e, sua trajetória ao longo dos anos. Além do mais, sabemos que documentos constituem uma boa parte da Cultura Material Escolar. Foi pensando nesta concepção que surge a implantação do CEMESSC, que contribui ainda mais para a preservação e socialização dos documentos escolares, auxiliando e cooperando para futuras pesquisas.

\title{
O CEMESSC E SUA CONTRIBUIÇÃO PARA A PRESERVAÇÃO E A PESQUISA NA HISTÓRIA DA EDUCAÇÃO
}

Antes de adentrar na implantação é importante salientar o principal fator que levou o GRUPEHME a tomar a decisão de criar o CEMESSC.

As pesquisadoras do GRUPEHME decidiram pela implantação do CEMESSC porque em suas pesquisas perceberam que a documentação mais antiga das escolas não recebia os cuidados adequados para sua preservação, o que 
coloca em risco o direito ao conhecimento da História da Educação das gerações que sucedem. Além da falta de cuidados adequados, outra realidade é a cultura do descarte, também presenciada nas escolas.

\section{A CULTURA DO DESCARTE COMO AMEAÇA AO PATRIMÔNIO ESCOLAR}

A cultura do descarte é algo muito presente na sociedade, e está relacionada ao consumo incentivado pelo capitalismo, onde a prática do descarte se dá inteiramente pela necessidade de consumo exagerado, assim buscando sempre algo que é novo. Segundo Marshall Berman, essa busca transformadora das coisas torna-se um risco. O autor afirma que "[...] mas ao mesmo tempo ameaça destruir tudo o que temos, tudo o que sabemos, tudo o que somos" (BERMAN, 2003, p. 15).

Compreende-se que grande parte da sociedade não busca preservar algo que fez parte do passado. Sem a noção da gravidade para suas identidades, muitas instituições vêm cada vez mais adquirindo este hábito, como também os educandários se desfazem dos materiais produzidos pelos sujeitos participantes das escolas, praticando, assim, a cultura de descarte.

Ao conhecer mais sobre a cultura material escolar e sua contribuição no âmbito da pesquisa histórica, percebe-se que boa parte das instituições educacionais não estão preservando como deveriam. Diana Gonçalves Vidal e Vera Lucia Gaspar da Silva salientam que os documentos participam decisivamente na produção e reprodução social, mas que vêm se tornando frágil, pois, os educandários não têm a prática de preservar e salvaguardar os acervos.

Tornou-se recorrente na socialização de trabalhos feitos com acervos desta natureza reclamações e desabafos sobre as más condições de acesso, a frágil organização da massa documental, a escassez de exemplares que possam testemunhar as práticas escolares. De todo modo, situação ainda mais "dramática" acomete os artefatos ou utensílios escolares que na maior parte das vezes foram descartados para dar lugar a novas aquisições ou por terem se tornados obsoletos na rotina escolar. Se por um lado livros e documentos impressos, ainda que escassos, são mais facilmente encontrados os exemplares de carteiras, lousas, globos, quadros parietais, abecedários e uniformes praticamente desapareceram da cena pública. (VIDAL e SILVA, 2011, p. 26)

Portanto, a ausência de exemplares dos artefatos escolares pode ser uma ameaça para diversos trabalhos relacionados às investigações em História da Criar Educação, Criciúma, v. 7, no2, jul/nov 2018.- PPGE - UNESC 
Educação, ou mesmo em áreas afins, pois a materialidade ajuda nos trabalhos de memória.

Muitos educandários simplesmente deixam seus documentos em lugares totalmente insalubres, sem nenhum cuidado. Os utensílios e imobiliários são trocados por novos, assim, sem nenhuma política institucional, estes artefatos acabam ficando a mercê da corrosão do tempo, perdendo-se e desintegrando-se por não haver cuidado algum.

Foi pensando na cultura de descarte que o GRUPEHME, por meio do CEMESSC, realizou um projeto de suma importância, um trabalho realizado de forma minuciosa, que tem como objetivo na preservação das fontes por meio da disponibilização dos documentos digitalizados como também nas imagens dos utensílios e mobiliários antigos.

\section{IMPLANTAÇÃO DO CEMESSC: INVENTARIAR, DIGITALIZAR E GUARDAR}

Para o início das atividades de implantação do CEMESSC, seguiram-se algumas etapas. A primeira foi o inventário das escolas estaduais mais antigas do sul de Santa Catarina, distribuídas em suas microrregiões. Em um primeiro momento alcançou-se a região AMREC - Associação dos Municípios da Região Carbonífera, depois se seguiu para a AMESC - Associação dos Municípios do Extremo Sul Catarinense e AMUREL - Associação de Municípios da Região de Laguna.

No segundo momento foram realizadas as visitas in loco, apresentando o projeto do CEMESSC para a gestão de cada escola e solicitando autorização para fotografar os prédios escolares, mobílias e utensílios, bem como os documentos textuais e iconográficos para que fossem digitalizados.

[...] Consideramos nessa pesquisa documentos com relevância histórica aqueles que apresentam um significado especial para a escola e que, por esse motivo foram guardados. Entendemos que todos os documentos possuem valor histórico, no entanto, em virtude do grande volume de algumas fichas de matrícula, livros caixas e outros similares, optamos metodologicamente em escolher alguns exemplares por décadas, levando os futuros navegadores do sitio a entrar em contado com a organização escolar do período. (RABELO e COSTA, 2011).

O grupo necessitou pensar um critério de escolha das escolas, nem todas as escolas dessas regiões foram envolvidas. $O$ critério de escolha deu-se na data de Criar Educação, Criciúma, v. 7, no2, jul/nov 2018.- PPGE - UNESC 
criação e emancipação dos municípios, para que fossem priorizados os municípios com maior tempo de existência ou emancipação.

Até o presente momento praticamente todas as escolas já foram visitadas e tiveram seus objetos, arquitetura e documentos digitalizados e fotogitalizados. Para que fosse possível digitalizar os documentos de diferentes dimensões e tipologias os deslocamos das escolas e fizemos todo o trabalho na universidade em equipamentos adequados (scanner). (RABELO e COSTA, 2011).

As microrregiões são constituídas de 42 municípios, que a princípio seria o número de escolas envolvidas. Segundo Rabelo e Costa (2011) isso não foi possível, pois apenas $57 \%$ das escolas foram visitadas. Todavia, não está descartada a hipótese de vir a serem todas as escolas envolvidas futuramente.

O CEMESSC abrange ao todo 27 escolas estaduais, localizadas nos municípios da AMREC, AMESC e AMUREL.

Das escolas envolvidas no projeto estão:

Tabela 1: AMREC - Associação dos Municípios da Região Carbonífera.

\begin{tabular}{|l|l|}
\hline \multicolumn{1}{|c|}{ ESCOLAS } & \multicolumn{1}{c|}{ MUNICÍPIOS } \\
\hline Escola de Educação Básica Costa Carneiro & Orleans \\
\hline Escola de Educação Básica Princesa Isabel & Morro da Fumaça \\
\hline Escola de Educação Básica Angelo Izé & Forquilhinha \\
\hline Escola de Educação Básica Professor Lapagesse & Criciúma \\
\hline Escola de Educação Básica Professor Padre Schuller & Cocal do Sul \\
\hline Escola de Educação Básica Salete Scotti dos Santos & Içara \\
\hline Escola de Educação Básica Visconde de Taunay & Lauro Muller \\
\hline Escola de Educação Básica Julieta Torres Gonçalves & Nova Veneza \\
\hline Escola de Educação Básica José do Patrocínio & Siderópolis \\
\hline Escola de Educação Básica Udo Deeke & Treviso \\
\hline Escola de Educação Básica Barão do Rio Branco & Urussanga \\
\hline
\end{tabular}

Tabela 2: AMESC - Associação dos Municípios do Extremo Sul Catarinense.

\begin{tabular}{|l|l|}
\hline \multicolumn{1}{|c|}{ ESCOLAS } & \multicolumn{1}{c|}{ MUNICÍPIOS } \\
\hline Escola de Educação Básica Castro Alves & Araranguá \\
\hline Escola de Educação Básica Pedro Simon & Ermo \\
\hline Escola de Educação Básica Jacinto Machado & Jacinto Machado \\
\hline Escola de Educação Básica Manoel Gomes Baltazar & Maracajá \\
\hline Escola de Educação Básica do Meleiro & Meleiro \\
\hline Escola de Educação Básica Bulcão Viana & Praia Grande \\
\hline Escola de Educação Básica Professora Maria Solange Lopes & São João do Sul \\
\hline
\end{tabular}

Criar Educação, Criciúma, v. 7, no2, jul/nov 2018.- PPGE - UNESC 


\begin{tabular}{|l|l|}
\hline de Borba & \\
\hline Escola de Educação Básica Catulo da Paixão Cearense & Sombrio \\
\hline Escola de Educação Básica Timbé do Sul & Timbé do Sul \\
\hline Escola de Educação Básica Jorge Schutz & Turvo \\
\hline Escola de Educação Básica Governador Ildo Meneghetti & Passo de Torres \\
\hline
\end{tabular}

Tabela 3: AMUREL - Associação dos Municípios da Região de Laguna.

\begin{tabular}{|l|l|}
\hline \multicolumn{1}{|c|}{ ESCOLAS } & \multicolumn{1}{|c|}{ MUNICÍPIOS } \\
\hline Escola de Educação Básica Marechal Luz & Jaguaruna \\
\hline Escola de Educação Básica Herćílio Luz & Tubarão \\
\hline Escola de Educação Básica Henrique Lage & Imbituba \\
\hline Escola de Educação Básica Professora Eulina Heleodora & Imaruí \\
Barreto & Braço do Norte \\
\hline Escola de Educação Básica Dom Joaquim &
\end{tabular}

As escolas foram escolhidas pelas organizadoras e coordenadoras do projeto, por meio de um acordo com as escolas, oficializadas por um Termo de Compromisso. Todas as instituições escolhidas foram visitadas por bolsistas juntamente com a presença de uma das coordenadoras do GRUPEHME. As escolas foram fotografadas e tiveram seus documentos levados para a digitalização, sendo este trabalho realizado no campus da UNESC. Após a digitalização dos documentos, o grupo os devolveu para as instituições de origem.

Vale ressaltar que:

No primeiro ano de execução do projeto, apesar da forte cultura do descarte foi encontrada uma diversidade de documentos que resistiram ao tempo, como: fotografias, hinos e históricos escolares, livros de matrícula, cadernos de desenho, fichas de alunos/as, livros-ponto. Somam-se a esses documentos vários livros de atas de: reuniões pedagógicas, conclusão de cursos, das APPs- Associações de Pais e Professores, dos Centros Cívicos, dos Grêmios Estudantis, dos Caixas Escolares, das Associações das Bibliotecas, dos Clubes Agrícolas, dos Clubes de Leitura, dos Jornais Escolares, dos Pelotões da Saúde, das Ligas da Bondade, das Ligas Prólíngua Nacional, de Exames Finais, dos Termos de Visitas dos Inspetores. Do mesmo modo, inventariamos, também, vários livros de registros: de Notas das Sabatinas, de Correspondência, de Honra ao Mérito, de Comunicações aos Pais, de Portarias e Decretos de Professores, de Avisos entre outros. (RABELO e COSTA, 2011).

Entre os documentos encontrados nas escolas, estão os livros de matrículas, neles podemos investigar os sujeitos que fizeram parte dos educandários, estando registrados os nomes, a idade, filiação e a série dos 
alunos/as, como também estando registrado o nome dos/as professores/as que lecionavam em determinada época.

Tais documentos trazem a relação do sujeito e os educandários. "As instituições escolares produzem uma imensidão de documentos que obedecem a uma ordem escriturística, sendo eles resultados das relações pedagógicas" (NICOLAU, 2012, p. 93), sendo assim, o CEMESSC busca por meio destas fontes mostrar o âmbito escolar enquanto cultura material, em um suporte virtual, preservando o original e também mostrando por meio da internet que é possível uma investigação, contribuição e auxilio em pesquisas. "[...] os historiadores da educação incorporaram a idéia de que a História se faz a partir de qualquer traço ou vestígio deixado pelas sociedades passadas" (LOPES e GALVÂO, 2005, p. 81). GRUPEHME, pensando nesta concepção, inventariou, digitalizou e guardou esses traços ou vestígios.

A digitalização preserva o original, pois evita o manuseio para não deteriorá-los. Porém não devemos deixar de lado a importância da preservação destas fontes, evitando a destruição dos objetos que fizeram parte dos educandários, sendo que não substitui o contato pessoal com as fontes.

[...] com as possibilidades e promessas da digitalização, a ameaça de outra destruição não se afastou definitivamente. Como leitores, como cidadãos, como herdeiros do passado, devemos, pois, exigir que as operações de digitalização não ocasionem o desaparecimento dos objetos originais e que seja sempre mantida a possibilidade de acesso aos textos tais como foram impressos e lidos em sua época. (CHARTIER, 2002, p. 29).

Depois de feita a escolha dos documentos, foram deslocados para um dos laboratórios da UNESC, com o auxílio das professoras e coordenadoras Giani e Marli, que ofereceram todo o apoio e suporte para as bolsistas envolvidas com o projeto.

[...] Este procedimento foi adotado para assegurar maior qualidade no processo de digitalização, pois na universidade há disponibilidade de um escâner mais apropriado para este fim. Antes de serem digitalizados, houve a remoção manual de encadernações, grampos e clipes, fitas adesivas além do conserto de páginas rasgadas dos documentos (quando possível). $\mathrm{Na}$ sequência, os documentos foram pré-classificados em arquivos específicos. (RABELO e COSTA, 2011).

Após esses procedimentos, passou-se para a próxima etapa, que foi a 
digitalização dos documentos. Todos os arquivos passaram por um tratamento das imagens, sendo realizada a compactação dos mesmos, pois esse processo de compactação reduz os tamanhos dos arquivos para o armazenamento de transferência, que passaram por um processo de tratamento das páginas e foram colocadas em formato de PDF.

Dando sequência ao trabalho, foram realizadas a identificação e catalogação dos arquivos, visando os dados e o âmbito de seu conteúdo. Documentos e conteúdos estão disponibilizados no Site do CEMESSC ${ }^{5}$ ou por meio do sistema de busca da biblioteca da UNESC. Com os dados selecionados pelas pesquisadoras, as coordenadoras do GRUPEHME tiveram o cuidado para que estes fossem devidamente selecionados a fim de não haver problemas legais, para que tudo saísse como planejado.

Sendo assim, pesquisadores/as selecionaram os documentos e os conteúdos para a alimentação do sistema juntamente com o auxílio da equipe da biblioteca da UNESC, com a finalidade de alimentar o acervo com todo cuidado, que além de ficar armazenados no sistema de busca também foram colocados em CDs.

Após a coleta dos dados, foi feito uma revisão do acervo juntamente com as bibliotecárias que nos deram todo o suporte e, trabalhando em conjunto, para que tudo saísse perfeitamente, um trabalho minuciosamente elaborado, onde exigiram muita dedicação e atenção de ambas as partes, depois deste procedimento, cada escola pronta foi armazenada em CDs, ficando distribuídas por: disponibilizados, não disponibilizados e documentos sem identificação, ou seja, três CDs por escolas. Sendo que, foi uma cópia dos CDs para as escolas, Biblioteca e para o acervo do CEMESSC.

O acervo do CEMESSC constitui-se como base de dados para várias pesquisas no campo da História da Educação, que busca oportunizar aos usuários do CEMESSC o contato com os novos conhecimentos científicos e tecnológicos, que interagem com a história e a memória, ampliando as pesquisas acadêmicas neste campo.

O CEMESSC tem como finalidade oferecer visibilidade, oportunizando o envolvimento de gestores, professores/as, alunos/as e pais na busca da história 
desses estabelecimentos educacionais.

Assim, o CEMESSC passa a ser um GUARDIÃO da Memória da Educação, contribuindo com a socialização da história da educação do Sul de Santa Catarina, com a comunidade e pesquisadores/as e principalmente com a preocupação em divulgar a importância da preservação do patrimônio e dos acervos escolares, abrindo as portas para novas investigações nesta área.

Com a utilização destes documentos temos várias possibilidades de pesquisas acadêmicas e científicas em diferentes áreas, não apenas histórica, mas também pedagógica, administrativa, arquivística entre outras áreas do conhecimento acadêmico.

No âmbito acadêmico desenvolveremos projeto de iniciação científica, trabalhos de conclusão de curso e dissertações no campo da História da Educação. Buscaremos oferecer oportunidade de ampliação do número de pesquisas acadêmicas que tratem de aspectos relacionados à História da Educação do sul de Santa Catarina. Também divulgaremos o CEMESSC em eventos científicos nacionais e internacionais e produziremos e publicaremos artigos científicos para as revistas da área de História da Educação. (RABELO e COSTA, 2011).

Compreende-se o papel fundamental e que dá base para esse projeto, onde tem contribuído cada vez mais para uma história crítica e investigativa acerca dos estudos relacionados com as práticas cotidianas nas instituições escolares. $O$ CEMESSC vem ao encontro do uso das novas tecnologias, trazendo para o pesquisador/a uma maneira simples e fácil, com o acesso em qualquer lugar, com muito empenho para que todos/as possam se beneficiar, tendo como auxílio o acervo por meio das mídias digitais, onde o sistema possa oferecer o que tem de melhor. Assim, mostrando e sensibilizado sobre a guarda do material produzido nos educandários.

O CEMESSC está no ar desde o ano de 2012, disponibilizado pelo sistema pergamum de busca da biblioteca da UNESC. Também se encontra inserido no site da página da UNESC, vinculado com o setor do MUESC - Museu Universitário do Extremo Sul Catarinense, na unidade do CEDOC - Centro de Documentação da UNESC - link Acervo CEMESSC.

\section{CONCLUSÃO}

Criar Educação, Criciúma, v. 7, no2, jul/nov 2018.- PPGE - UNESC 
Por meio desse estudo, pode-se compreender a importância em preservar os documentos escolares. A partir dessa investigação tive o discernimento sobre os conceitos de cultura material escolar, memória e identidade. O que é a cultura material escolar e qual o seu alcance nos estudos da história da educação, onde busca entender e explicar esse campo em seus mais variados aspectos.

Pude observar o descaso que os arquivos escolares vêm sofrendo, sem que as gestões tenham alguma política de preservação para salvaguarda deste patrimônio escolar. Assim, o GRUPEHME me proporcionou adentrar neste universo de conhecimento e percepção de uma realidade que ainda se faz presente nas instituições escolares.

O CEMESSC oportunizou a preservação e a valorização da nossa herança cultural escolar, por meio da digitalização e arquivando os documentos encontrados nas escolas, assim proporcionando o direito à memória para gerações futuras.

O grupo busca, com a implantação do CEMESSC, contribuir para o fortalecimento da cultura escolar, e que as instituições escolares possam valorizar a sua história. Pois o projeto visa a preservação dos documentos por meio das mídias digitais, mas o trabalho de preservar os acervos dessas instituições sobre os documentos impressos e de objetos escolares é inteiramente dos educandários de origem, por isso o grupo ressalta a sensibilidade de pensar em ações que atuem no campo da preservação do patrimônio escolar, movendo para os sujeitos envolvidos nas escolas a guarda da materialidade produzida por elas.

O CEMESSC possibilitará, no âmbito acadêmico, muitos projetos de iniciação científica, trabalhos de conclusão de curso e dissertações no campo da História da Educação, pois está pautado em uma concepção que busca a valorização de todos os sujeitos envolvidos no processo de escolarização, ou seja, uma perspectiva da história social em diálogo com a história cultural.

A implantação do CEMESSC por meio do GRUPEHME, buscando com oficinas, orientarem as gestões das escolas para a importância dos documentos, bem como de que forma realizar sua guarda e conservação. 


\section{REFERÊNCIAS}

ALCÂNTARA, Wiara Rios et al. Educação, história e cultura escolar: a pesquisa como processo formativo do estudante de (Pós) Graduação. In: Cultura material escolar: a escola e seus artefatos (MA, SP, SC e RS, $1870-1925)$. São Luiz: EDUFMA; Café\&Lápis, 2011.

ARAUJO, Mairce da. Alfabetização patrimonial e práticas de ensino: os setenta anos da E. M. Raul Veiga. In: Memórias e Patrimônios: experiências em formação de professores. Rio de Janeiro: EDUERJ, 2009.

BENCOSTA, Marcus Levy Albino. A cultura escolar na historiografia da educação brasileira: Alcances e limites de um conceito. In: Cultura Material, Migrações e Cidadania. Porto: Sociedade Portuguesa de Ciências da Educação, 2010.

BERMAN, Marshall. Tudo que é sólido desmancha no ar. São Paulo: Companhia das Letras, 2003. p. 15-35.

CHARTIER, Roger. A história ou a leitura do tempo. Belo Horizonte: Autêntica Editora, 2009.

CHARTIER, Roger. Os desafios da escrita. São Paulo: UNESP, 2002.

FARIA FILHO, Luciano Mendes; GONÇALVES, Irlen Antônio; VIDAL, Diana Gonçalves. A cultura escolar como categoria de análise e como campo de investigação na história da educação. Educação e Pesquisa, São Paulo, v. 30, n. 1, jan./abri. 2004. p. 139-159.

FELGUEIRAS, Margarida Louro; VIEIRA, Carlos Eduardo (Orgs.). Cultura Escolar: da migração do conceito à sua Objectivação Histórica In: . Cultura Material, Migrações e cidadania. Porto: Sociedade Portuguesa de Ciências da Educação, 2010.

FISCHMAN, Gustavo E.; CRUDER, Gabriela. Fotografias escolares como evento na pesquisa em Educação. Revista Educação e Realidade, Porto Alegre, n. 28, p. 3953. jul./dez., 2003.

KOSSY, Bóris. Fotografias e história. São Paulo: Editora Ática S.A., 1989.

LE GOFF, Jacques. Documento/Monumento. In: . História e Memória. 4 ed. Campinas, SP: UNICAMP, 2003.

LOPES, Eliane Marta Teixeira; GALVÃO, Ana Maria de Oliveira. Fontes e História da Educação. In: Rio de Janeiro: DP\&A, 2001. 
LOPES, Eliane Marta Teixeira; GALVÃO, Ana Maria de Oliveira. História da educação. 2.ed. Rio de Janeiro: DP\&A, 2005.

NICOLAU, Fabiana. Produzindo fontes para história carnavalizada: as instituições e cultura escolares In: História, Educação e Cultura Escolar. Chapecó: Argos, 2012.

NORA, Pierre. Entre memória e história: a problemática dos lugares In: Projeto História, São Paulo, v. 10, p. 7-28, dez./1993.

PESEZ, Jean-Marie. História da Cultura Material In: A História Nova. 5 ed. São Paulo: Martins Fontes, 2005.

RABELO, Giani; COSTA, Marli de Oliveira. Inventariar, digitalizar, guardar: A preservação da história da educação no Sul de Santa Catarina. In: XXVI SIMPÓSIO NACIONAL DE HISTÓRIA - AMPUH, 2011, São Paulo. Anais Eletrônicos... São Paulo: USP, 2011. Disponível em:

<http://www.snh2011.anpuh.org/resources/anais/14/1300964050_ARQUIVO_artigoc ompletoanpuh2011.pdf>. Acesso em: 19 de nov. 2013.

SANTOS, Heloisa Meirelles dos. Centro De Memória Institucional: a cultura escolar nos arquivos. Rio de Janeiro, 2011. Disponível em: <www.cemiiserj.blogspot.com>. Acesso em: 19 de nov. 2013.

SANTOS, Jose Luiz dos. O que é cultura. 16 ed. São Paulo: Brasiliense, 1996.

SANTOS, Myriam. O Pesadelo da Amnésia Coletiva: um estudo sobre os conceitos de memória, tradição e traços do passado. RCBS, n. 23, ano 8, outubro de 1993.

SAVIANI, Dermeval. Breves considerações sobre fontes para a história da educação. Revista HISTEDBR On-line, Campinas, n. especial, p. 28, ago. 2006. Disponível em:

$<$ http://www.histedbr.fae.unicamp.br/revista/edicoes/22e/art5_22e.pdf>. Acesso em: 26 de set. 2013.

SCHELLENBERG, T. R. Arquivos modernos: princípios e técnicas. Rio de Janeiro: Fundação Getúlio Vargas, 2004.

VIDAL, Diana Gonçalves. SILVA, Vera Lucia Gaspar. Por uma história sensorial da escola e da escolarização. In: . Cultura material escolar: a escola e seus artefatos (MA, SP, SC e RS, 1870 - 1925). São Luiz: EDUFMA; Café\&Lápis, 2011. 